\title{
ROLE OF MODIFIED ALVARADO SCORING IN ACUTE APPENDICITIS AND ITS HISTOPATHOLOGICAL CORRELATION IN GOVERNMENT VELLORE MEDICAL COLLEGE HOSPITAL
}

\author{
K. Shantha Kumar ${ }^{1}$ \\ ${ }^{1}$ Associate Professor, Department of General Surgery, Government Vellore Medical College Hospital.
}

\section{ABSTRACT}

\section{BACKGROUND}

Acute Appendicitis is a more common surgical emergency encountered in a day-to-day surgical practice. There are many methods for diagnosis of acute appendicitis, both by clinically and radiologically.[1] The delay in diagnosis usually leads on to various complications that causes increase in both morbidity and mortality of the patient.

The aims of this study is to study the effectiveness of modified Alvarado score in acute appendicitis and to correlate the same with post-operative histopathological report in acute appendicitis.

\section{MATERIALS AND METHODS}

In this study, 100 patients with features suggestive of acute appendicitis were included. Modified Alvarado score is used for scoring the patients and their post-operative histopathological features were evaluated and ' $\mathrm{p}$ ' value is calculated accordingly about $\mathrm{p}=$ 0.0001 which is found to be significant by chi square test.

\section{RESULTS}

Among the 100 patients, the prevalence of acute appendicitis is more commonly seen in patients who scored $>7$ (41/46), i.e. about $89 \%$. The patients with score between 5 and 7 were found to be within the reactive lymphoid hyperplasia group (30/42), i.e. about $71 \%$. The patients with score 1 - 4 was found to be in the group of reactive lymphoid hyperplasia $(7 / 12)$ i.e. $58.3 \%$ and others with unremarkable pathology (5/12) i.e. $41.7 \%$.

\section{CONCLUSION}

Modified Alvarado score is used in diagnosing acute appendicitis (13) and with score $>7$ is most commonly seen with acute appendicitis by post-operative histopathological report and patients with score 5 - 7 are observed and followed up (12). Those with score 1 - 4 are being observed have shown less chances of appendicitis.

\section{KEYWORDS}

Acute appendicitis; modified Alvarado; histopathology report.

HOW TO CITE THIS ARTICLE: Kumar KS. Role of modified Alvarado scoring in acute appendicitis and its histopathological correlation in Government Vellore Medical College Hospital. J. Evolution Med. Dent. Sci. 2016;5(95):7005-7008, DOI: 10.14260/Jemds/2016/1584

\section{BACKGROUND}

Acute appendicitis is seen in a day-to-day practice in emergency department. It is one of the commonest surgical emergency met out. It can sometimes confuse the practitioners by its presentation. The delay in early diagnosis or failure in early diagnosis may happen many times. This may lead on to the disease prognosis. This will further lead on to increase in morbidity as well as occasional mortality in the patient, though there are many recent trends in investigatory modalities. Diagnosis of acute appendicitis is still a mystery.[2][3]

This may lead to increase in operative indication for the patient due to the fear of complication followed by it. There is increase in the negative appendicectomy rate of about $20 \%$ seen in literature.(4)

Financial or Other, Competing Interest: None.

Submission 06-10-2016, Peer Review 19-10-2016,

Acceptance 21-10-2016, Published 28-11-2016.

Corresponding Author:

Dr. K. Shantha Kumar,

Associate Professor

Department of General Surgery,

Government Vellore Medical College \& Hospital.

E-mail: drkskumarmmc@gmail.com

DOI: $10.14260 / j e m d s / 2016 / 1584$

\section{(c) (1) $(9)$}

Therefore, a scoring system was developed by Alvarado in 1986. This is used for the diagnosis of acute appendicitis, thereby reducing the rate of negative appendicectomy without causing increase in morbidity and mortality.[5]

\section{AIMS OF THE STUDY}

1. To study the effectiveness of modified Alvarado score in acute appendicitis.

2. To correlate the modified Alvarado score with postoperative histopathological examination in acute appendicitis.

\section{MATERIALS AND METHODS}

This study includes the population of 100 patients. The 100 patients are those who attended the emergency department from August 2014 to July 2015. The scoring system used is modified Alvarado scoring system. One of the criteria in this scoring system is not evaluated or dropped out. This is because of the facility of non-availability of the criteria, i.e. shift of neutrophils to the left as an emergency measure. All other criteria were taken into consideration. All those patients admitted in the emergency department were included in the study. Routine examination was carried out after obtaining the history from them. This also includes obtaining the history for criteria of modified Alvarado scoring system. Patient's gynaecological and urological were excluded from the study 
population. All the 100 patients were evaluated by using modified Alvarado scoring system. Then they were subjected to surgery and followed by histopathological report; out of 100 patients all the 100 patients were undertaken for surgery. The modified Alvarado score was calculated according to the presenting feature of the patient in the emergency department. The calculation of modified Alvarado score is divided into three grading,

- Grade 1: values 1 to 4 .

- Grade 2: values 5 to 7 .

- Grade 3: values more than 7 .

The grading is calculated and they are correlated with histopathological reports. They are further analysed and tabulated in the following variables. The variables are as follows,

- Age.

- Modified Alvarado scores.

- Pre-operative evaluation/score.

- Post-operative histopathological reports.

All the patients were followed routinely for the period of 6 months and then they were reviewed monthly.

\section{OBSERVATION AND RESULTS}

The study population of this study is about 100 patients. The 100 patients had undergone classical appendicectomy.

\section{Age Distribution}

The incidence of acute appendicitis in the study population fall into 5 major groups. In this the incidence is maximum in 21 30 age group (of about $42 \%$ in the 2 nd decade of life). The least incidence of occurrence is seen in $51-60$ age group (of about $2 \%$ in the 5 th decade of life). This shows the incidence of acute appendicitis, classically seen in the age group of 21 - 30 due to the increase in the presence of clinical cases in this age group.

\section{Distribution According to Modified Alvarado's Scoring}

In this study, the patient's clinical features/symptoms are included. Aged patients in this study were presented with right iliac fossa tenderness with $96 \%$ had right iliac fossa pain, pyrexia (36\%), leucocytosis were presented only in a little proportion, anorexia, nausea/vomiting were seen in highest number of cases of about $78 \%$ and $72 \%$ respectively.

\begin{tabular}{|c|c|c|}
\hline $\begin{array}{c}\text { Modified Alvarado's } \\
\text { Components }\end{array}$ & No. of Cases & $\%$ \\
\hline Right iliac fossa pain & $96 / 100$ & $96 \%$ \\
\hline Anorexia & $78 / 100$ & $78 \%$ \\
\hline Nausea/Vomiting & $72 / 100$ & $72 \%$ \\
\hline RIF tenderness & $100 / 100$ & $100 \%$ \\
\hline Rebound tenderness & $64 / 100$ & $64 \%$ \\
\hline Pyrexia & $36 / 100$ & $36 \%$ \\
\hline Leucocytosis & $68 / 100$ & $68 \%$ \\
\hline $\begin{array}{c}\text { Table 1. Modified Alvarado Components } \\
\text { and its Percentage }\end{array}$ \\
\hline
\end{tabular}

This shows that in the study population all are not presented in a single patient and symptoms varies in different proportion. This shows the Alvarado components constitute of about varying degree of occurrence according to the severity of illness.

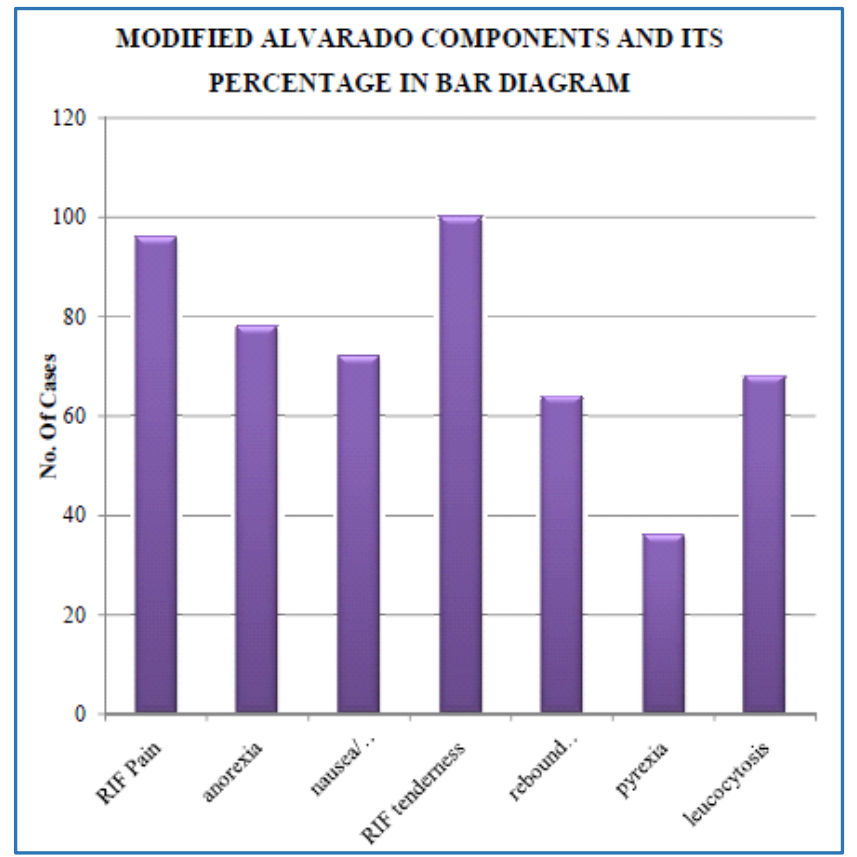

Distribution of Modified Alvarado Scores

This scoring increases the type of involvements of patients according to the severity of infection. In this study population, about $46 \%$ of patients $(46 / 100)$ were seen to be in the scoring of about $>7$.

\begin{tabular}{|c|c|c|}
\hline \multirow{2}{*}{ Modified Alvarado Score } & \multicolumn{2}{|c|}{ Total } \\
\cline { 2 - 3 } & No. of Case & $\mathbf{\%}$ \\
\hline $1-4$ & 12 & $12 \%$ \\
\hline $5-7$ & 42 & $42 \%$ \\
\hline$>7$ & 46 & $42 \%$ \\
\hline Total & $\mathbf{1 0 0}$ & $\mathbf{1 0 0 \%}$ \\
\hline Table 2. Distribution of Modified Alvarado Score \\
\hline
\end{tabular}

About $42 \%$ of study population were in the scoring of about 5 - 7 (42/100). The least incidence is seen in about $12 \%$ $(12 / 100)$, is seen in the scoring value of about $1-4$. This denotes the presence of severity of symptoms seen in the worthy, the study group of about $46 \%(46 / 100)$ and to the level of $42 \%(42 / 100)$.

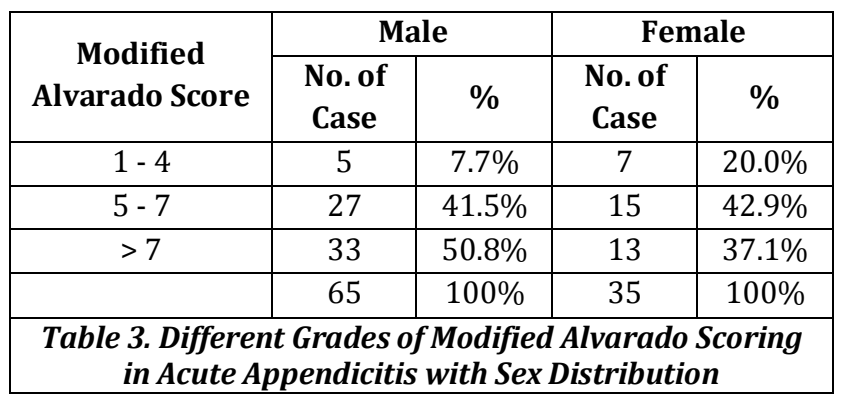

According to modified Alvarado scoring, about 50.8\% $(33 / 65)$ of the patients were in the score of $>7$ in the male and $37.1 \%(13 / 35)$ in females.

Out of the patient in scoring 1 - 4, i.e. 12 patients $(12 / 100)$ there is $5 / 12$ (7.7\% of males) and $7 / 12$ (20\% of females). There are about $42 \%(42 / 100)$ in the scoring of about $5-7$, of this (41.5\%) $27 / 42$ were males and (42.9\%) $15 / 42$ were females. 


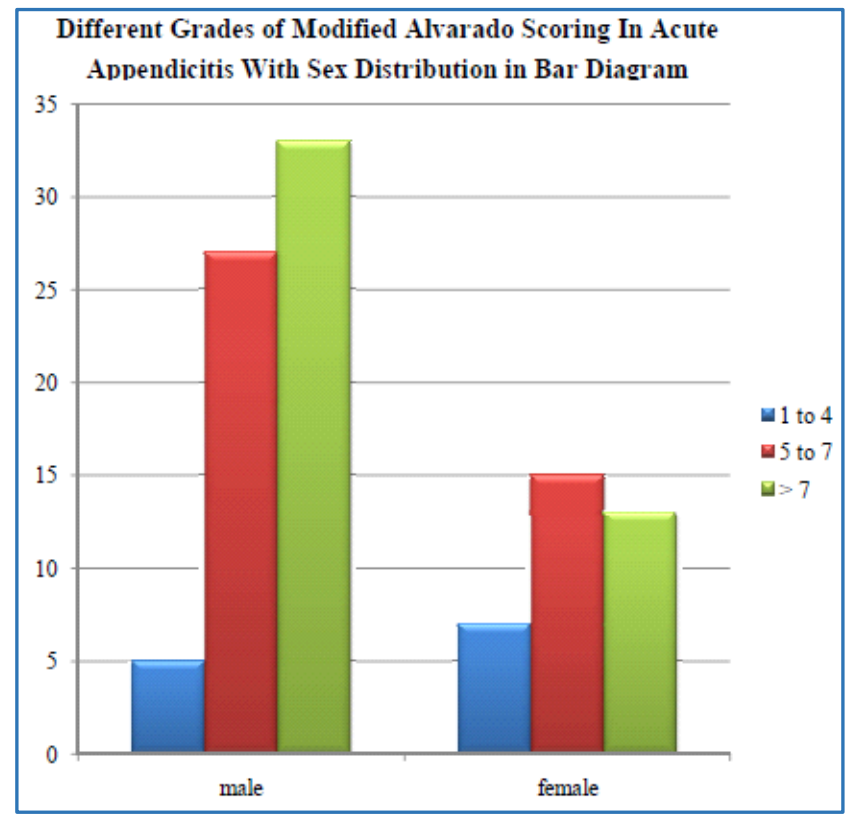

Histopathological Correlation with modified Alvarado Scoring

The following are the observation made with the histopathological reports of the patients who have undergone appendicectomy after Alvarado scoring.

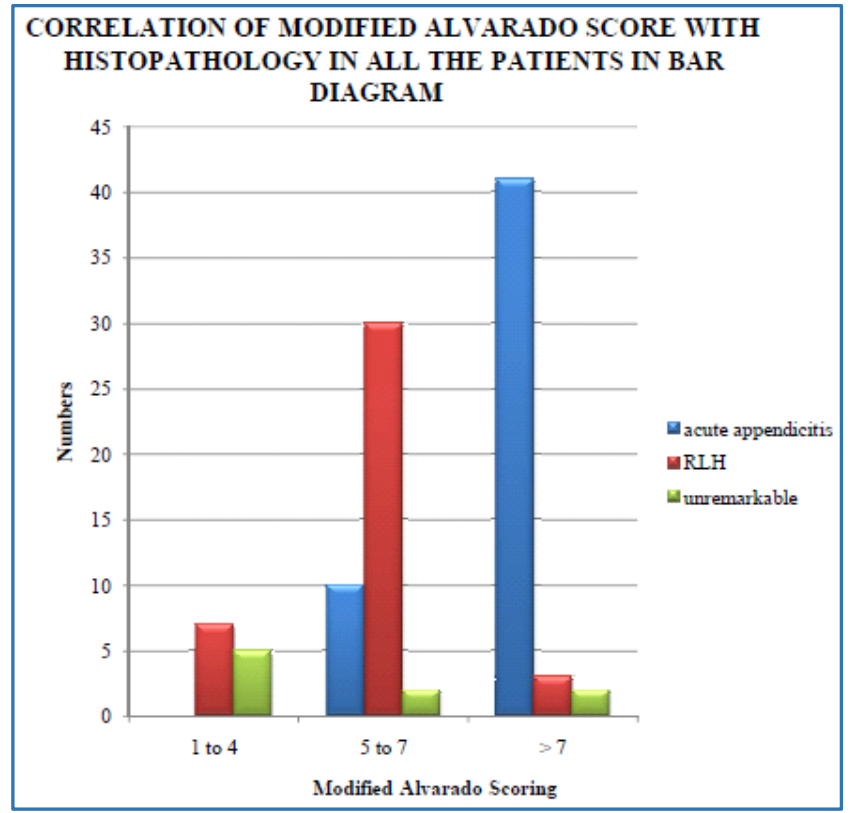

The correlation of score $5-7$ of both the sex, that is about 71.4\%. Patients came there with reactive lymphoid hyperplasia, which contribute of $(30 / 42)$ patients followed by $23.8 \%$ patients with acute appendicitis of $(10 / 42)$ patients. The unremarkable pathology in this is $(2 / 42)$ patients of $4.8 \%$.

In patients with $>7$ score, acute appendicitis correlate to about $89.1 \%$ (41/46) patients; reactive lymphoid hyperplasia is seen in $6.5 \%(3 / 46)$ and unremarkable features is seen in $4.4 \%(2 / 46)$ of patients in this category.

These stages and correlations of ' $p$ ' values is about ( $p=$ 0.0002 ), which is very significant calculated by using chi square test of association.

It shows that reactive lymphoid hyperplasia is seen in about $73.3 \%$ (11/15) patients with scoring of about 5 - 7 and
$20 \%(3 / 15)$ patients with acute appendicitis in the scoring of about $5-7$ and $6.7 \%(1 / 15)$ patients with unremarkable pathology in this group.

It shows that significant correlation of about $100 \%$ $(13 / 13)$ patients is seen in score of $>7$ in the histopathological correlation following acute appendicitis in female. This shows a ' $p$ ' value of about $(p=0.0001)$ in this group of population, which is tested by using chi square test of association. The ' $p$ ' value is very significant from correlating in this group of people.

\section{CONCLUSION}

Modified Alvarado scoring is a good diagnostic scoring system used in a day-to-day practice by all clinicians.[6] It is a scoring system used for evaluation of acute appendicitis with score of less than 4 . Those whose scoring system is between 5 to 7 , they are kept under observation and they are surveyed and reexamined for every 2 hours for the score to be increasing or decreasing. ${ }^{[7][8]}$ It is to be taken as an added feature for an additional investigation to be carried out in this category of people like CT abdomen and the survey can be decided after additional investigations are obtained.[9][10] The plan for surgery (i.e.) emergency appendicectomy is recommended for the patients for score of more than 7. They are further managed and investigated post-operatively with histopathological correlation.[11][12]

Correlation of scoring with histopathology report was done. Simultaneously. the scoring of more than 7 shows the histopathological positivity of about $89 \%$ and $6.5 \%$ have been shown to be presented with reactive lymphoid hyperplasia. The unremarkable histopathology correlates to about $4.4 \%$. It was found to be the patients with Alvarado scoring of about 4 - 7 with about $71.4 \%$. About $23.8 \%$ and $4.8 \%$ are those who presented with reactive lymphoid hyperplasia[13][14] and unremarkable histopathological feature.

The patient with scoring $1-4$ presented with reactive lymphoid hyperplasia and unremarkable feature corresponds to about $58.3 \%$ and $41.7 \%$ in this scoring system respectively. Hence, we finally recommended to say that usage of modified Alvarado scoring system is used in the clinical diagnosis of acute appendicitis in the emergency department. This causes reduction in false negative operation.[14][15]

There are many other modalities/investigations for the diagnosis of acute appendicitis, but clinical correlation was found to be superior to all clinically than all this investigations.[16] The other investigations are used only in additive/supportive informatory measures. They are most commonly used for confirmation in case of doubtful diagnosis.[17][18]

In patient admitted with diagnosis of acute appendicitis, modified Alvarado scoring system has been used. When the score is more than 7 , appendicectomy is planned. When the score is $5-7$, the patient is re-evaluated after sometime or with some other investigations. When the score is $1-4$, then they can be usually observed and can be discharged with acceptable false negative results in this group.

\section{REFERENCES}

1. Fitz RH. Perforating inflammation of the vermiform appendix with special reference to its early diagnosis and treatment. Am J Med Sci 1886;92:321-46. 
2. Schwartz SI, Shires GT, Spencer FC. Principles of surgery. $6^{\text {th }}$ edn. New York: Mcgraw-Hill Inc 1994:1307-18.

3. Teicher I, Landa B, Cohen M, et al. Scoring system to aid in diagnoses of appendicitis. Ann Surg 1983;198(6): 753-9.

4. Bell MJ, Bower RJ, Ternberg JL. Appendicectomy in childhood. Analysis of 105 negative explorations. Am J Surg 1982;144(3):335-7.

5. Deutsch AA, Shani N, Reiss R. Are some appendicectomies unnecessary? J R Coll Surg Edinb 1983;28(1):35-40.

6. Wagner JM, McKinney WP, Carpenter JL. Does this patient have appendicitis? JAMA 1996;276(19):1589-94.

7. Alvarado A. A practical score for the early diagnosis of acute appendicitis. Ann Emerg Med 1986;15(5):557-64.

8. Owen TD, Williams H, Stiff G, et al. Evaluation of Alvarado score in acute appendicitis. J R Soc Med 1992;85(2):87-8.

9. Lone NA, Shah M, Wani KA, et al. Modified Alvarado score in diagnosis of acute appendicitis. Indian Journal for the Practising Doctor 2006:3(2).

10. Jones PF. Suspected acute appendicitis: trends in management over 30 years. B J Surg 2001;88(12):1570-7.

11. Macklin CP, Radcliffe GS, Merei JM, et al. A prospective evaluation of modified Alvarado score for acute appendicitis in children. Ann $\mathrm{R}$ Coll Surg Engl 1997;79(3):203-5.
12. Al-Fallouji MAR. Postgraduate Surgery. The Candidate's Guide. $2^{\text {nd }}$ edn. Oxford: Butterworth-Heinemann 1998: 388-9.

13. Addiss DG, Shaffer N, Fowler BS, et al. The epidemiology of appendicitis and appendicectomy in the United States. Am J Epidemiol 1990;132(5):910-25.

14. Kjossev KT, Losanoff JE. Duplicated vermiform appendix Br J Surg 1996;83(9):1259.

15. Fenyo G, Lindberg G, Blind P, et al. Diagnostic decision support in suspected acute appendicitis: validation of a simplified scoring system. Eur J Surg 1997;163(11):831- 8.

16. Ohmann C, Yang Q, Franke C. Diagnostic scores for acute appendicitis. Abdominal Pain Study group. Eur J Surg 1995;161(4):273-81.

17. Al Qahtani HH, Muhammad AA. Alvarado score as an admission criterion for suspected appendicitis in adults. Saudi J Gastroenterol 2004;10(2):86-91.

18. Chang FC, Hogle HH, Welling DR. The fate of negative appendix. Am J Surg 1973;126(6):752-4. 